\title{
Optimization of Aluminum Optical Table Production
}

\author{
Jakub Cerveny, Michal Povolny \& Lubos Kroft
}
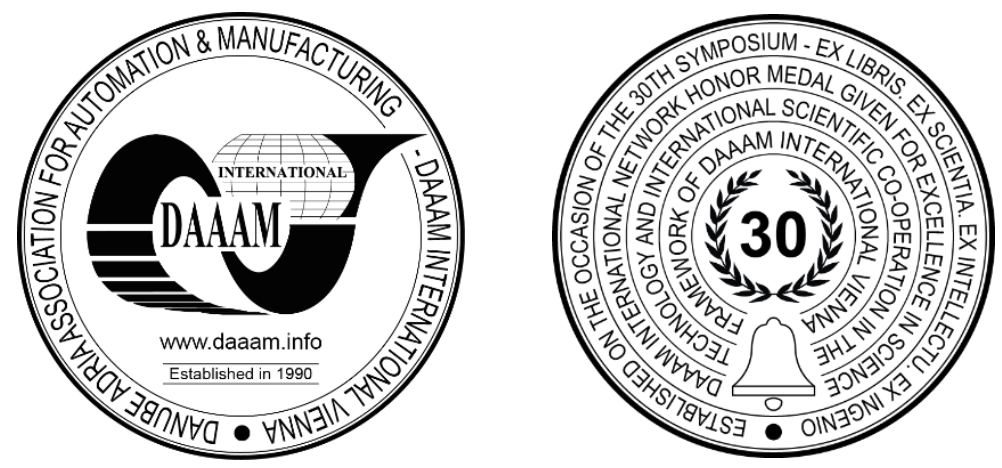

This Publication has to be referred as: Cerveny, J[akub]; Povolny, M[ichal] \& Kroft, L[ubos] (2021). Optimization of Aluminum Optical Table Production, Proceedings of the 32nd DAAAM International Symposium, pp.0631-0639, B. Katalinic (Ed.), Published by DAAAM International, ISBN 978-3-902734-33-4, ISSN 1726-9679, Vienna, Austria DOI: $10.2507 / 32$ nd.daaam.proceedings.089

\begin{abstract}
Machining of aluminum optical tables is a current topic due to its relevance to laboratory research in the field of laser technology, but also in the pharmaceutical or chemical industries. The purpose of this article is to present proposals to produce aluminum optical tables using modern machining methods focused on the production of holes and threads with qualitative aspects for the use of optical tables in vacuum atmosphere. Firstly, the main product, the machine and the original production method will be introduced. Subsequently, modern methods and tools for potential production improvement will be introduced. The third part deals with an experiment focused on the creation of threaded holes and their qualitative evaluation. The last part evaluates the economic aspect of production. To summarize the results, it is impossible to neglect the fact that innovations in cutting tools for aluminum alloys are a big step forward in mechanical engineering. The impact these tools have on production is very much needed, especially in industries such as the laser industry, where high demands are placed on quality, which is amplified by using optical tables in a vacuum. At the same time, they have a very positive effect on the economic aspect of production, which cannot be neglected while planning a production.
\end{abstract}

Keywords: Optical table; Aluminum alloy; Drilling; Threading.

\section{Introduction}

Today, production requirements are increasing at a very fast pace. It is mainly about quality, quantity, and accuracy with constant correction by economic factors. This increase in requirements is due to technological development, which brings new innovative methods of production. Some sectors of the machinery industry are more affected by this trend than others. It all depends on the range of production and possible results. The vacuum equipment industry, which is the subject of this article, is one of the areas that must respond promptly to customer requirements. It is mainly about increasing the requirements for accuracy, quality, and economy of production. The production of aluminum optical tables, that are used in vacuum chambers, entails several technological tasks, and therefore production requirements. This work will focus on the appropriate choice of tools for the technology of making holes and threads. Research is made for company Streicher, spol s r o. where production of optical tables takes place. Aim of this research is to recommend to the company new strategies of production based on using modern tools that can combine more then just one machining technology. Tools must be suitable for machining of alluminium alloys and to be able to fulfil qualitative aspects of production for products that will operate in vacuum atmosphere. Therefore, tools will be most probably coated in thin layers and specifically constructed for this type of machining. Machining conditions will be also tested and recomended based on corporate machinery. [1], [2] 


\section{Optical table:}

It serves as a clamping plate for various devices and equipment. Devices are connected to table by screws. There are many threads, evenly distributed over the entire table area. Optical tables for vacuum chambers have additional specific requirements due to their use. This applies to the requirement to degas the material. This means the release of particles into the vacuum space from a material while gas is pumped out of the vacuum chamber. When creating a vacuum, an effort is made to keep the number of particles of a certain size as small as possible contained in a certain volume. Degassing degrades the vacuum value due to the increase of particles in the chamber space.
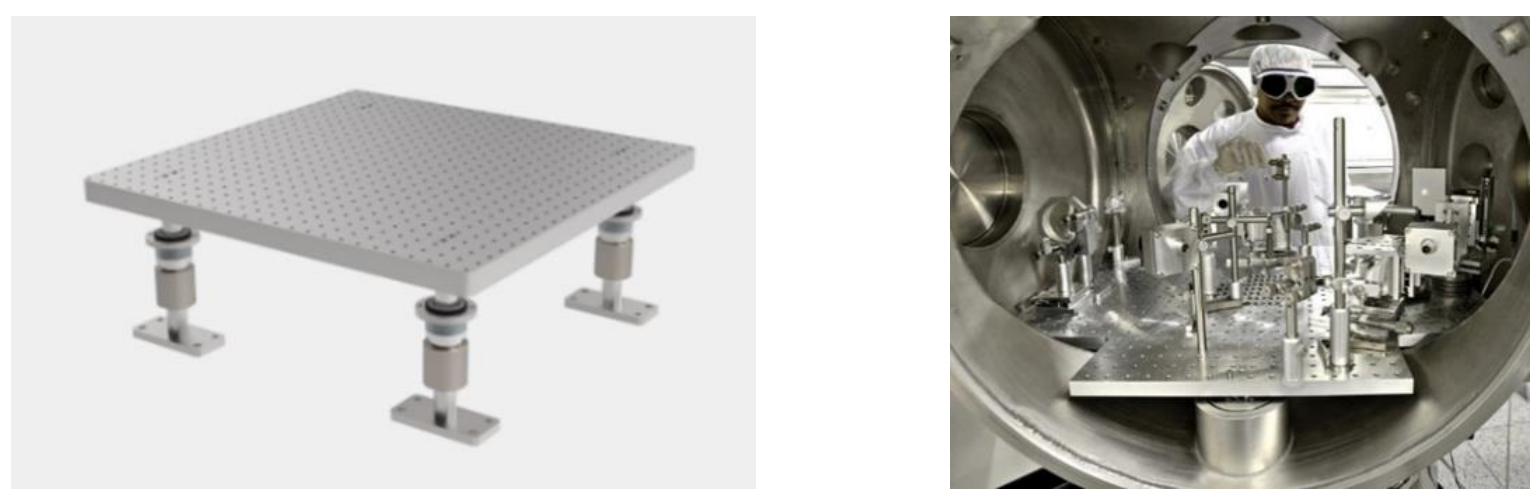

Fig. 1. Optical table on supports and in use [3], [4]

\section{Semi-finished product:}

The semi-finished product to produce the optical table is cast milled plate of aluminum alloy EN AW 5083.

\section{Machine:}

Production will take place on a horizontal milling machine Soraluce SLP 8000. This is a machine suitable especially for machining larger workpieces. For this reason, the maximum possible machine speed of $5000 \mathrm{rpm}$ is low and therefore not ideal for production of holes with M6 threads.

\section{Original concept of production:}

The original proposal to produce optical tables was to divide individual technological operations among specialized tools for each of them. The production process consisted of creating a hole using a DC150-05-05.000A1-WJ30RE drill, subsequent countersinking using a $90^{\circ}$ HSSE conical countersink and Enorm1-AL-GLT-8 M6 tapping. This is a procedure for creating impenetrable holes with M6 threads of a $15 \mathrm{~mm}$ depth.

\section{New concept of production:}

Due to the development of the machine industry, there are better production options than the use of many singlepurpose tools. The improvement is mainly in the possibility of combining technological operations performed by only one multi-purpose tool. This aspect of production brings a great reduction in the machining process itself, not only the time when the tool is in contact with the workpiece, but especially at the time of transitions and other secondary times, which will significantly affect the total machining time. Among these times, tool adjustment and replacement times must be considered. If the production process is so technologically advanced that the secondary times cannot be influenced anymore, there remains a need to focus on shortening the main times during which the tool meets the workpiece. The initial modification is the choice of a machine that allows better production conditions. In this case there is a problem with the use of machine with low spindle speed. It is possible to supply the machinery equipment with an accelerating head, which will allow the spindle speed to double at least. [3], [4]

\section{Variant 1}

The first option for improving and optimizing production is to design combined tools. These tools consist of a combined drill that combines drilling and countersinking operations, and a tapping cutter that adds a threading operation to these operations. The use of a combination drill will reduce the number of tools required by one and the use of a milling cutter by two. A lower number of tools provides very substantial reduction in production times, which means an economic advantage and possibly a hiher production productivity. The reduction of production times is caused by the elimination of tool change times, which also causes the reduction of transition times between individual holes, as well as the reduction of additional times associated with the adjustment and maintenance of tools and the times of machining itself. Thus, in general, there is no reduction in fixed costs, as more modern tools tend to be more expensive and structurally complex, but this leads to a reduction in variable costs, which are specified as the cost of producing individual piece. Based on this change, there is an advantage especially in such production, where there are as many products as possible. In the eventual solution of this work, the construction of the optical table itself brings economic advantage when using combined tools with an increasing number of holes in the product. 


\section{Variant 2}

The second option is to use the same combined tools that will be used in variant 1 with the addition of an accelerator head. The accelerator head is a machinery that allows you to increase the maximum speed of the machine spindle. This increase leads to improved machining productivity. At the same time, it should improve production, as higher speeds are recommended when machining aluminum alloys. Increased productivity means faster production and thus economic benefits. In the case solved in this work, it will be an expected increase from $5000 \mathrm{rpm}$ to $12,000 \mathrm{rpm}$. Due to the higher purchase price of the accelerator head and the smaller time differences that its use will bring compared to the optimization with the combined tools from variant 1, it is expected to show the advantage of this variant after a larger number of produced holes.

\begin{tabular}{|c|c|c|c|}
\hline \multirow{2}{*}{ Variants: } & \multicolumn{2}{|c|}{ Processes and tools } & \multirow{2}{*}{$\begin{array}{l}\text { Using the } \\
\text { accelerator head }\end{array}$} \\
\hline & Driling and countersinking & Threading & \\
\hline $1 \mathrm{~A}$ & Drill - DC260-03-05.000A0-WJ30ET & Tap -N205166-M6 & No \\
\hline $1 \mathrm{~B}$ & Drill - DC260-03-05.000A0-WJ30ET & Tap - Enorm1-AL-GLT-8 M6 & No \\
\hline $1 \mathrm{C}$ & \multicolumn{2}{|c|}{ Milling cutter BGF VHM IKZ HB M6 - 2,5xD } & No \\
\hline $2 \mathrm{~A}$ & Drill - DC260-03-05.000A0-WJ30ET & Tap -N205166-M6 & Yes \\
\hline $2 \mathrm{~B}$ & Drill - DC260-03-05.000A0-WJ30ET & Tap - Enorm1-AL-GLT-8 M6 & Yes \\
\hline $2 \mathrm{C}$ & \multicolumn{2}{|c|}{ Milling cutter BGF VHM IKZ HB M6 - 2,5xD } & Yes \\
\hline
\end{tabular}

Table 1. Description of different variants

\section{Experiment:}

\begin{tabular}{|c|c|c|c|c|c|}
\hline \multirow{2}{*}{ Variants: } & \multicolumn{4}{|c|}{ Processes and tools } & \multirow{2}{*}{$\begin{array}{l}\text { Using the } \\
\text { accelerator } \\
\text { head }\end{array}$} \\
\hline & Drilling and countersinking: & $\begin{array}{c}\text { Speed } \\
{[\mathrm{min}-1]}\end{array}$ & Threading: & $\begin{array}{c}\text { Speed } \\
{[\text { min-1] }}\end{array}$ & \\
\hline $1 \mathrm{~A}$ & $\begin{array}{l}\text { Drill - DC260-03-05.000A0- } \\
\text { WJ30ET }\end{array}$ & 5000 & Tap -N205166-M6 & 1000 & No \\
\hline $1 \mathrm{~B}$ & $\begin{array}{l}\text { Drill - DC260-03-05.000A0- } \\
\text { WJ30ET }\end{array}$ & 5000 & 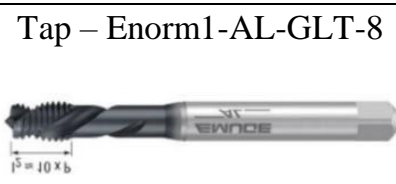 & 1000 & No \\
\hline $1 \mathrm{C}$ & Threading cutter BC & VHM IF & HB M6 - 2,5xD & 5000 & No \\
\hline $2 \mathrm{~A}$ & $\begin{array}{l}\text { Drill - DC260-03-05.000A0- } \\
\text { WJ30ET }\end{array}$ & 12000 & Tap -N205166-M6 & 1500 & Yes \\
\hline $2 \mathrm{~B}$ & $\begin{array}{l}\text { Drill - DC260-03-05.000A0- } \\
\text { WJ30ET }\end{array}$ & 12000 & Tap - Enorm1-AL-GLT-8 & 1500 & Yes \\
\hline $2 \mathrm{C}$ & Threading cutter BC & VHM IF & HB M6 - 2,5xD & 12000 & Yes \\
\hline
\end{tabular}

Table 2. Overview of tools for each variant [5], [6], [7], [8], [9] 
The aim of the experiment is to determine the economic cost of individual variants of optical table production and to verify the functionality of the proposed solutions. The experiment was divided into several stages. First, aluminum plates were machined by specified methods. Subsequently, they were cut with a water jet into smaller pieces and milled in the center of predetermined holes for the possibility of subsequent measurement. The measurements of the produced holes were performed on a microscope and a roughness gauge/profilometer.

\begin{tabular}{|c|c|c|c|}
\hline \multirow{2}{*}{ Variants: } & \multicolumn{2}{|c|}{ Production time [h:min:s] } & \multirow{2}{*}{ Total time [h:min:s] } \\
\cline { 2 - 4 } & Drilling and countersinking: & Threading: & $6: 40: 36$ \\
\hline 1 A & $3: 20: 48$ & $3: 19: 48$ & $6: 40: 36$ \\
\hline 1 B & $3: 20: 48$ & $3: 19: 48$ & $10: 53: 18$ \\
\hline 1 C & $2: 25: 48$ & $3: 01: 48$ & $5: 27: 36$ \\
\hline 2 A & $2: 25: 48$ & $3: 01: 48$ & $5: 27: 36$ \\
\hline 2 B & \multicolumn{2}{|c|}{$10: 53: 18$} & \\
\hline
\end{tabular}

Table 3. Production times

\section{Technical evaluation:}

Tool wear was measured with a KEYENCE VHX-6000 optical microscope with a maximum magnification of up to 1000 times and compared individual instruments before and after the production process, which amounted to 2304 repetitions of the technological operation, according to a certain instrument.
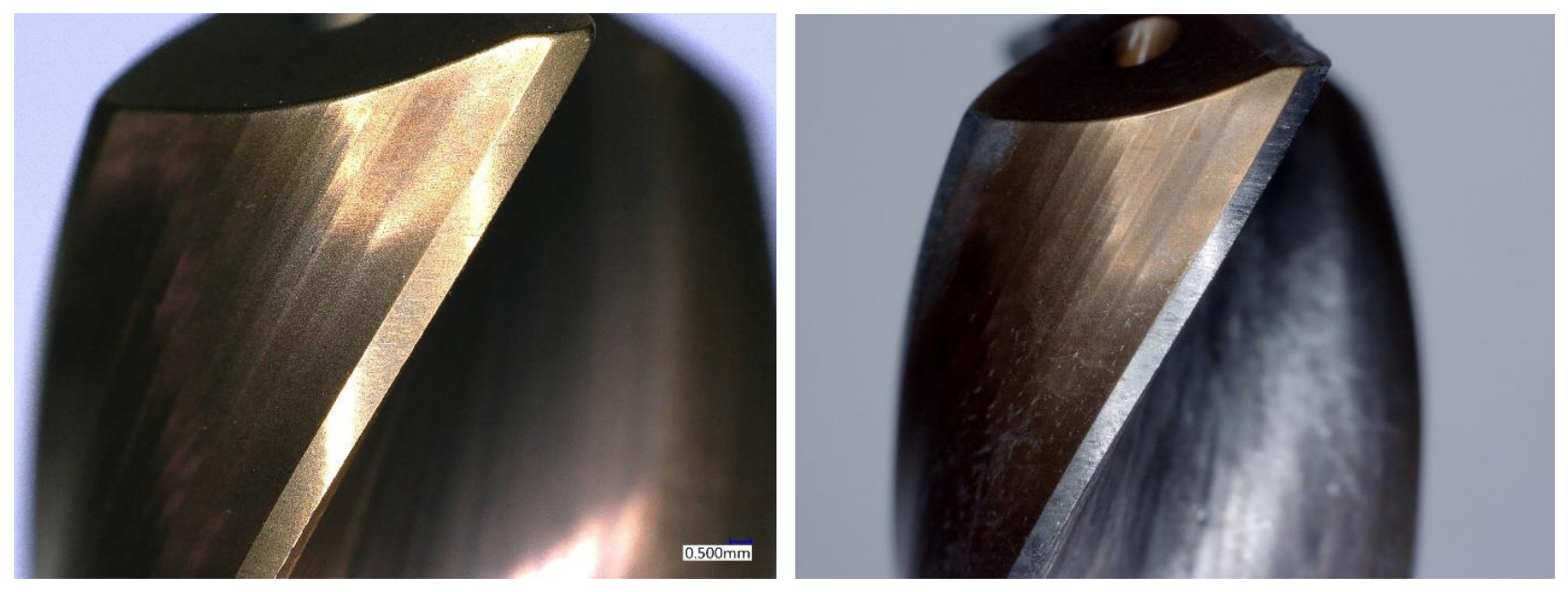

Fig. 2. Tool wear of drill observed on microscope

The drill shows no signs of wear. The only visible change is the change in color due to heat and abrasion. Apart from the visual difference, the change in color does not bring any change related to the quality of production.
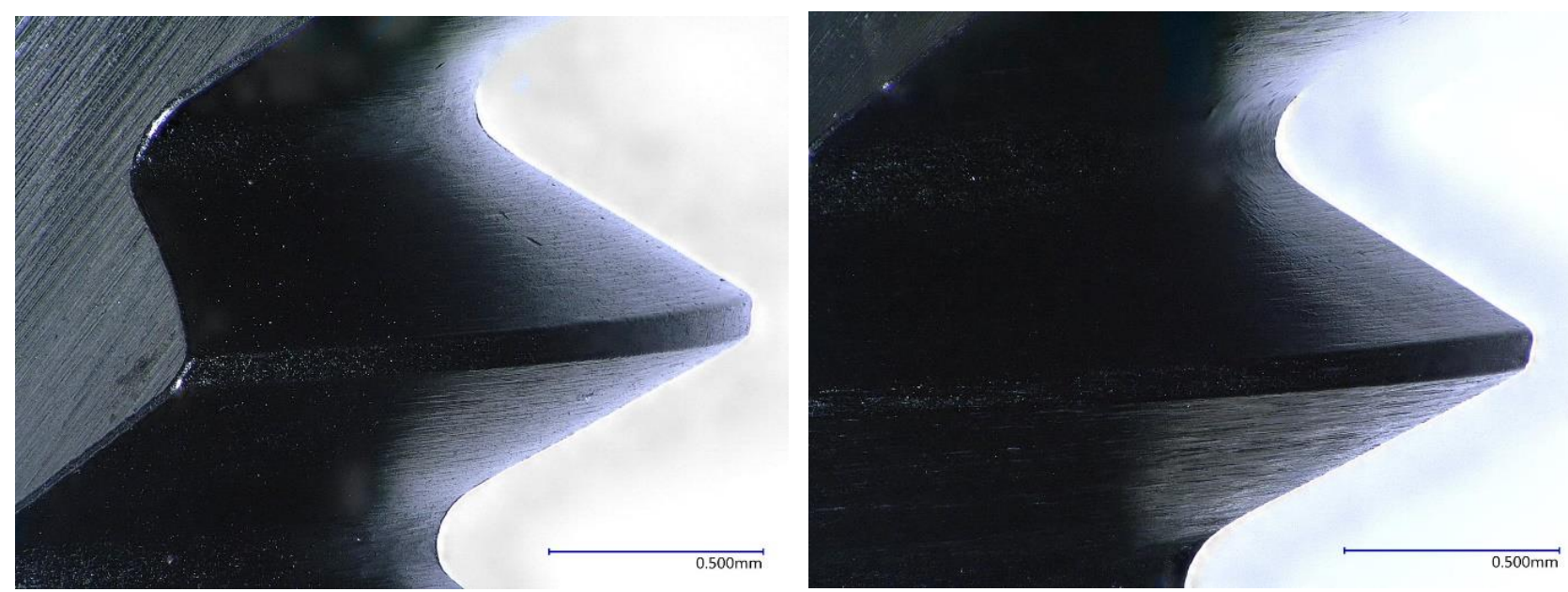

Fig. 3. Tool wear of tap observed on microscope 
Walter and Emunge taps have the same characteristic when progressing in time. This is a phenomenon in which the tool geometry is smoothed after performing a certain number of operating cycles. This phenomenon has a positive effect on machining and on product quality. As with the drill, the negative effects did not appear. It can be assumed that the taps and the drill will have an extreme service life when used for machining the aluminum alloy from which the optical tables are made. From this assumption we can evaluate the wear of the tool as a minor aspect of production, which does not require much attention and does not occur as a control and decision parameter in the economic evaluation of production.

\section{Quality of threads measured on microscope:}

The quality of the threads, as well as the wear of the tools, was measured on an optical microscope. The microscope allows you to measure 3D elements of the thread and then evaluate the pitch, roughness, angle of inclination and height of the tooth of the thread. Individual samples were observed at 100 times magnification, and then at 200 times magnification. At 100 times magnification, 3 threads were photographed in a 3D image. At 200 times magnification, only one thread was photographed and similarly converted to $3 \mathrm{D}$ and evaluated. The comparison led to the conclusion that none of the threading methods showed better results than the others.

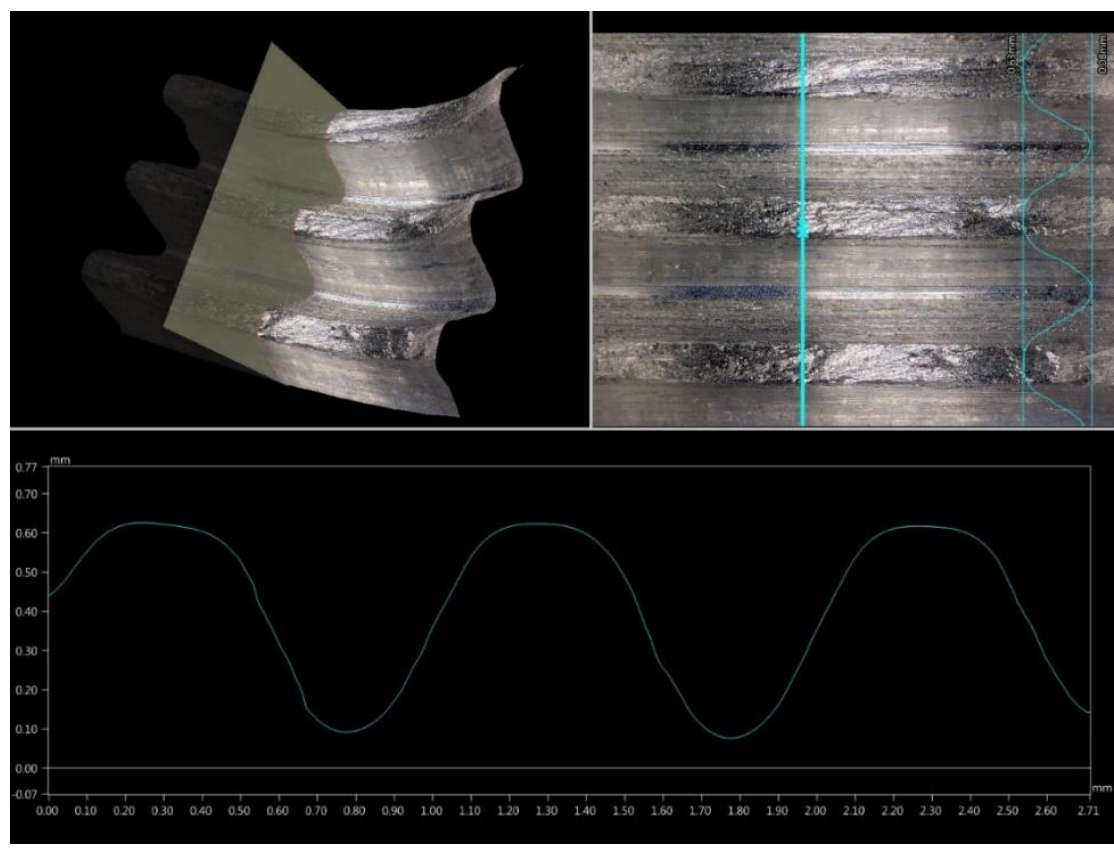

Fig. 4. 100 times magnifitcation of threads observed on microscope

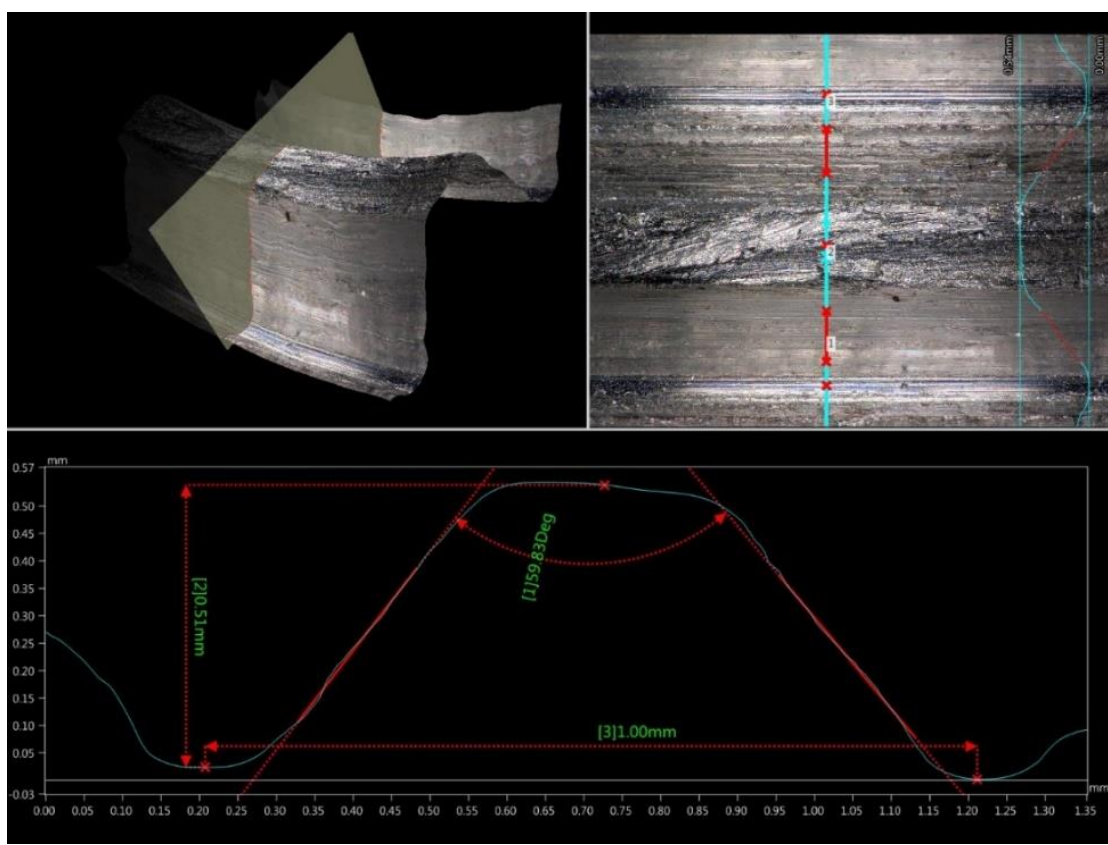

Fig. 5. 200 times magnification of thread observed on microscope 
The similarity and technically different results could be caused by two reasons. One reason could be the true technical similarity with minimal deviations in the measured parameters, and thus the qualitative conformity of the threads regardless of the production method. The other reason could be an unsuitable measurement method and insufficient accuracy of the measuring device, which cannot distinguish the monitored elements and leads to misleading measurement results. For verification, the threads were also remeasured with a roughness gauge/profilometer. The differences between the 49th, 1,152th and 2,256th threads are minimal and do not indicate the need to run the tool before production or, conversely, the loss of quality due to wear.

\section{Quality of threads measured on roughness tester/profilometer:}

Measurements on a Hommel Etamic T8000 roughness tester/profilometer achieve greater accuracy than measurements on an optical microscope. The values measured by this device are therefore more authoritative than the values measured on a microscope. The disadvantage of the roughness gauge/profilometer is the inability to convert the measurement into a 3D model for visual evaluation and comparison of the thread area. The measurement was performed again for all variants on all pieces representing individual predetermined holes. Threads were measured at $10 \mathrm{~mm}$. Measurements of the roughness on the roughness tester/profilometer resulted in verification of the observation on the microscope. The possibility of invalid results due to inaccuracy of microscopic measurements was ruled out. Nevertheless, the measurement with a roughness gauge/profilometer remains more authoritative precisely due to the mentioned inaccuracies of the microscope.

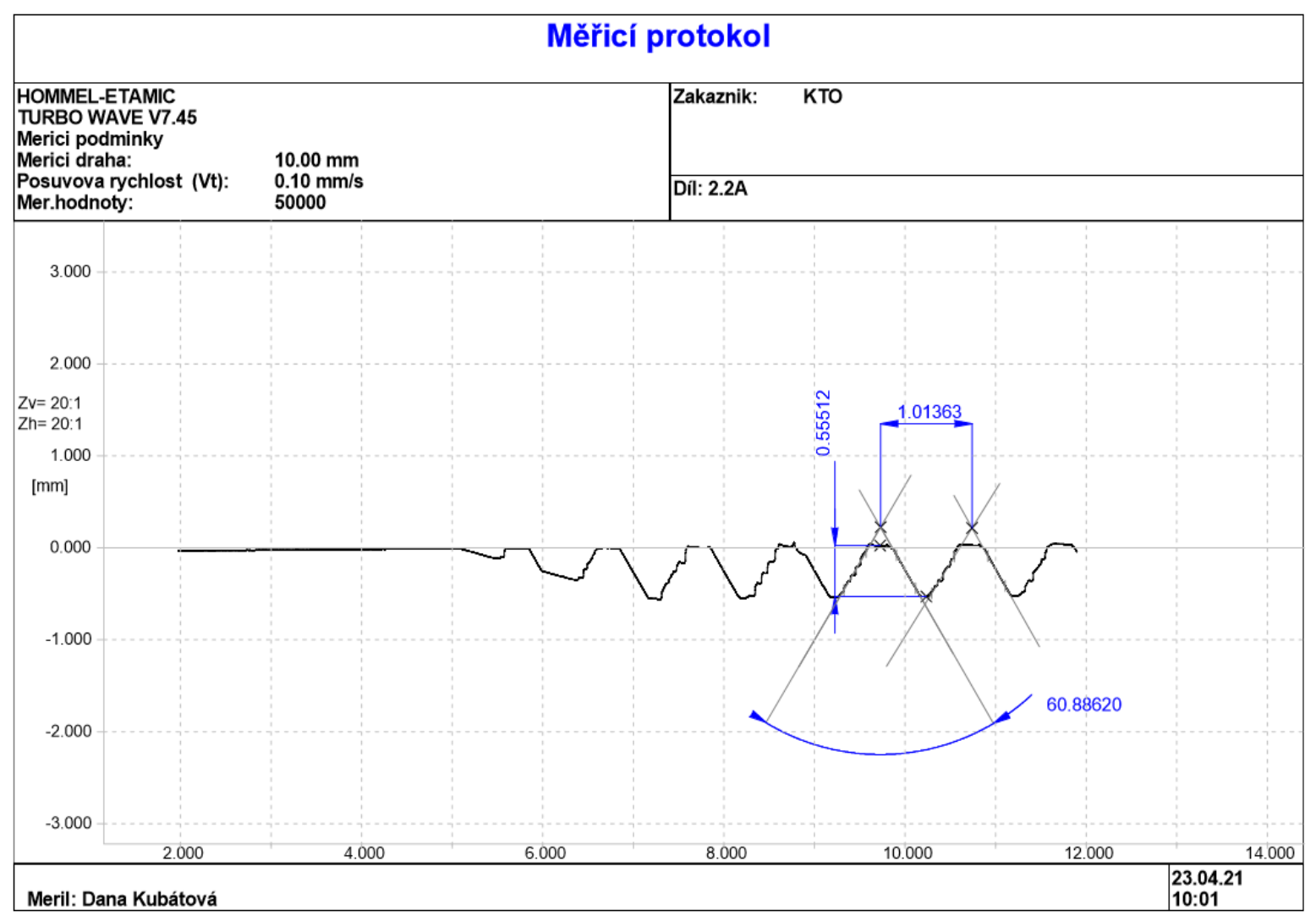

Fig. 6. Observation on roughness tester/ profilometer

\section{Economical evaluation:}

\begin{tabular}{|c|c|}
\hline \multirow{2}{*}{ Variants: } & Number of holes corresponding to the turning point Q: [pcs] \\
\cline { 2 - 2 } & Hourly rate of the machine 2000 Kč/h \\
\hline 0x1A & 628 \\
\hline 0x1B & 897 \\
\hline 0x2A & 21541 \\
\hline 1Ax2A & 107652 \\
\hline 1Cx2A & 17352 \\
\hline
\end{tabular}

Table 4. Economical turning points 
The economic evaluation is focused on the production price for individual variants in comparison with the original variant. For each variant, turning points were calculated to determine the advantage of the pairs of variants relative to each other. [8]

\section{Grafical evaluation of different concepts of production:}

The graphical comparison shows the economic suitability of the individual variants. Based on the turning points, the variants can be compared with each other and tey can determine from which production volume which of the variants will be advantageous. The points cannot be determined with sufficient precision from the graphs, so they were calculated in the previous table. The graphs are used to clearly verify the calculated values and to easily distinguish the advantages of the compared variants. Variants $1 \mathrm{~B}$ and $2 \mathrm{~B}$ were not included in the graphs due to their clearly distinguishable disadvantages compared to variants $1 \mathrm{~A}$ and $2 \mathrm{~A}$.

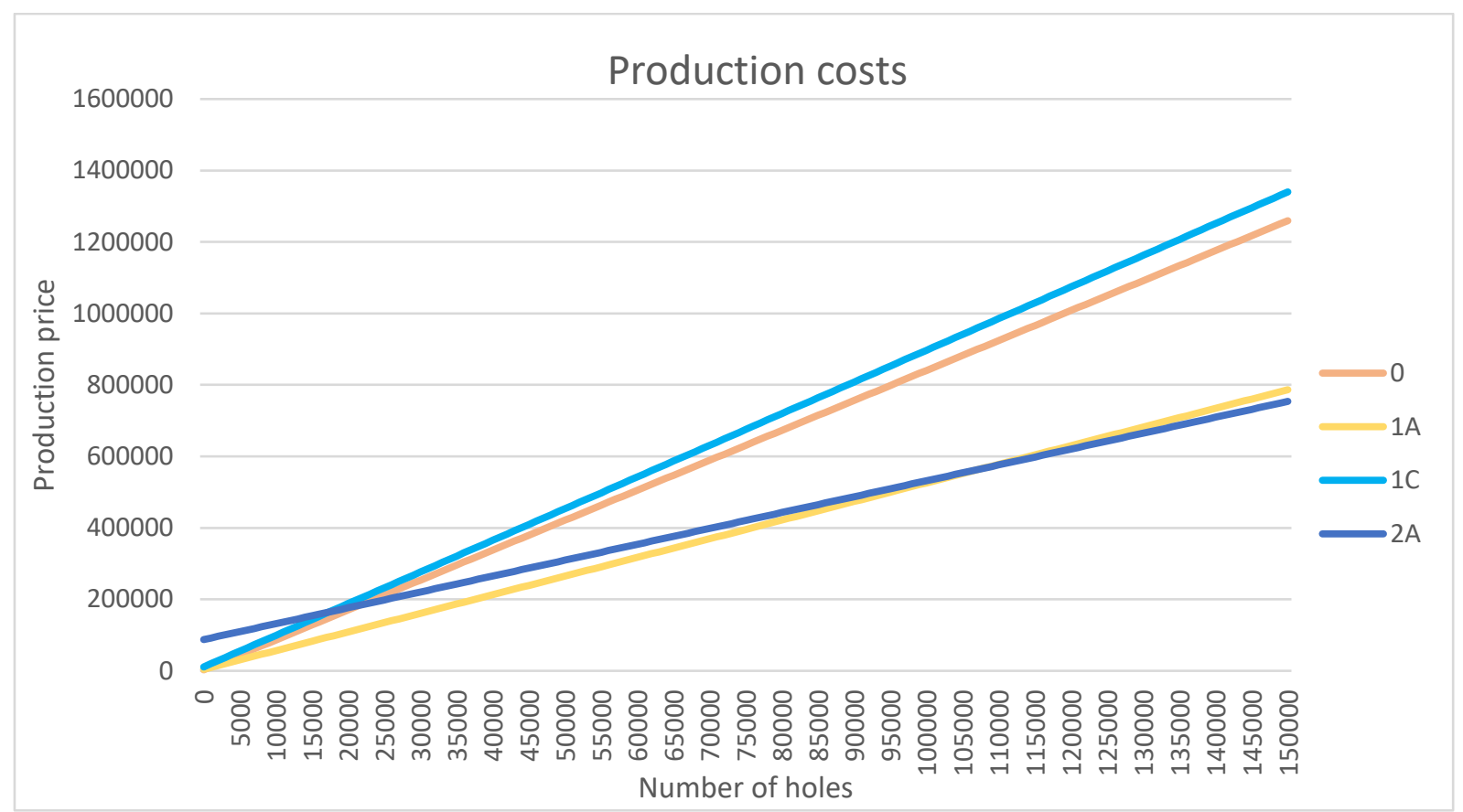

Fig. 7. Graph of production cost

Variants $1 \mathrm{~A}$ and 2A are the most economically advantageous variants. The difference is visible in the reduced required number of holes produced for the economic advantage of the variants. This is the position of the turning point with a value of 107,652 produced holes, which again confirms the previous calculations. In conclusion, a comparison of the economic advantages of all proposed production variants, considering the hourly rate of the machine of CZK 2,000/hour, resulted in 4 variants $1 \mathrm{~A}, 1 \mathrm{~B}, 2 \mathrm{~A}$ and $2 \mathrm{~B}$, from which variants $1 \mathrm{~A}$ and $2 \mathrm{~A}$ are best based due to their fixed costs. The advantage is reversed between these variants for the number of holes, which is the value of 107,652 holes produced. For a lower number of productions, variant $1 \mathrm{~A}$ is more advantageous and for a higher volume variant $2 \mathrm{~A}$. Other variants were evaluated as economically disadvantageous.

\section{Conclusion:}

The aim of this article was to propose the optimization of the technology of production of aluminum optical tables. The optimization proposal consisted of the design of 6 new methods of holes and threads prodction, which differed from one another by production tools and machining conditions. This was followed by the experiment and its verification from a qualitative and an economic point of view. To ensure the qualitative aspect of the proposed variants, tools designed for machining non-ferrous metals, especially for aluminum and its alloys, were selected. The economic suitability of the designs was focused on reducing production times. Initially, the proposals focused on minimizing downtime, which corresponds to crossing times and tool changes. A secondary aspect was shortening of the main times, which correspond to the machining times when the tool meets the workpiece.

The original method did not show sufficient signs of modernization that today's machinery industry offers. It used only single-purpose tools for each operation separately, namely it separated the drilling, countersinking and threading operations. The newly designed variants consisted in the use of modern combined tools, which can combine these operations into one production cycle. Due to the differences of the tools, three variants were proposed. The first two used a combined drill, which drilled and countersinked the hole in one operating cycle, and then the thread was cut with two different taps. 
The third variant used a thread milling cutter, which is designed to perform all production operations of the threaded hole during one cycle. For these variants, such conditions were proposed that they correspond to the maximum possible speed of the production machine on which the newly introduced production will take place. Furthermore, the extension of machine accessories with an accelerating head was proposed, which managed to increase the maximum speed of the machine spindle. The machining conditions were adapted to this increase and these were subsequently applied to the previous three variants

After the completion of the design and determination of the machining parameters, an experiment was performed, which put the individual proposed variants into practice. Test plates made of EN AW 5083 material were machined, which corresponded to the material of the manufactured optical tables. 2,304 holes with M6 threads were drilled into each plate. Testing was performed on a DMG MORI DMU 65 monoBlock machine, which was able to simulate the speed before and after using the accelerator head.

The machined plates were then cut into smaller pieces with a water jet and milled through the center of predetermined holes to allow subsequent observation on a KEYENCE VHX-6000 microscope and a Hommel Etamic T8000 roughness tester/profilometer. The results of the experiment showed a qualitative agreement of the threads produced by the individual variants. Another qualitative aspect of the evaluation was the determination of tool wear. Wear did not occur in any of the variants that used a combined drill - for this reason, a high tool life is assumed. For machining with a thread milling cutter at lower spindle speeds, the tool broke and thus the experiment did not occur under increased cutting conditions. The cutter broke during the hole drilling operation, probably due to insufficient cutting fluid pressure, which left loose chips in the cut, on which the cutter rested and broke while drilling.

The economic evaluation of the experiment, which was focused on the comparison of individual variants in terms of fixed and variable costs, led to the determination of variants with a combined drill and tap Walter as the most economically advantageous. The advantage is determined by the value of 107,652 produced holes for an hourly rate of the machine of 2,000 CZK/hour in favor of the variant without an accelerating head before reaching this production volume. In case of exceeding this volume of yield, an economically more advantageous variant with an accelerating head is issued. The original variant and variants using thread cutters have proven to be unsuitable. For this reason, variants with combined drill and tap Walter will be recommended to the firm Streicher, spol. s.r.o. Pilsen based on their production to perform machining with the best qualitative and economical aspects.

Next step of research is focused on milling operation. Milling is also taking place in machining of aluminum optical tables. Use of these products in vacuum atmosphere puts higher demands on milling operation as well as drilling, countersinking, and threading. Therefore, the research will lead to finding the best way and tools for machining of the optical tables. [10], [11]

\section{Acknowledgments}

I would like to thank to the co-authors of this paper for all their help and personal interest in this work. I would also like to thank to the colleagues from STREICHER spol. s.r.o. Pilsen, a company this research was done for, for their advice and all the support they have provided.

This article was created under the project SGS-2019-008: Research and Development for Innovation in the Field of Manufacturing Technology - Machining Technology III.

\section{References}

[1] Buranska, E[va] \& Buransky, I[van] (2018). Cutting Environment Impact on the Aluminium Alloy Machining (DFA), Proceedings of the 29th DAAAM International Symposium, pp.1158-1163, B. Katalinic (Ed.), Published by DAAAM International, ISBN 978-3-902734-20-4, ISSN 1726-9679, Vienna, Austria DOI: 10.2507/29th.daaam.proceedings. 166

[2] Steininger, A., Siller, A., Bleicher, F. (2014) Investigations regarding process stability aspects in thread tapping Al-Si alloys, Available from: https://www.scopus.com/record/display.uri?eid=2-s2.084937032739\&origin=resultslist \&sort=plf $\&$ src $=$ s $\&$ sid $=a 15 \mathrm{cbf7e} 20 \mathrm{a} 92 \mathrm{e} 56 \mathrm{f} 8168 \mathrm{a} 2535 \mathrm{fba} 248 \& \operatorname{sot}=\mathrm{b} \& \mathrm{sdt}=\mathrm{b} \& \mathrm{sl}=3$ $8 \& s=\mathrm{KEY} \% 28$ machining+tools+threads+aluminium\%29\&relpos=4\&citeCnt=19\&searchTerm $=$ Accessed: 2014$11-26$

[3] www.binteractiv.cz, www cliquo cz. (2021) Laser center ELI Beamlines test the most poverfull laser on earth. Laserové centrum ELI Beamlines už testuje nejvýkonnější laser na světě a brzy zahájí plný provoz. Je to šance i pro vědce z Liberce. Available from: https://tuni.tul.cz/rubriky/veda-a-vyzkum/id:103812/laserove-centrum-elibeamlines-uz-testuje-nejvykonnejsi-laser-na-svete-a-brzy-zahaji-plny-provoz-je-to-sance-i-pro-vedce-z-liberce Accessed on: 2021-01-05

[4] Streicher, spol s $\quad$ r $\quad$ o. (2020) Modular Vacuum Chamber. Streicher. Available from: https://www.scubechamber.com/ Accessed on: 2020-12-26

[5] Walter tools. Walter (2021) DC260-03-05.000A0-WJ30ET - Step drills - ToolsUnited. Available from: https://www.toolsunited.com/App/EN/Article/ArticleDetailsPage/181022154023869 Accessed on: 2021-0505 
[6] Emuge high performance tools (2021) Enorm 1-AL-GLT-8 | Emuge-Franken Website Available from: https://www.emuge-franken-group.com/gb/en/thread-technology/machine-tap/enorm-1-al-glt8/p/000000000010418138 Accessed on: 2021-05-23

[7] Walter tools. Walter - N205166-M6 (2021) Taps with reinforced shank - ToolsUnited Available from: https://www.toolsunited.com/App/EN/Article/ArticleDetailsPage/24696400130374852 Accessed on: 2021$05-23$

[8] DC260-03-03.300A0-WJ30ET (2021) Combined drill., Sdružený vrták obrázek Available from: https://www.boie.de/dc260-03-a0-zidPRD-17927 Accessed on: 2021-05-05

[9] Synek, Miloslav (1999) Business administration. in Prague, Podniková ekonomika. V Praze: C.H. Beck, 2006. ISBN 978-80-7179-892-7.

[10] Kroupa, T[omas]; Dana, M[ilan] \& Zetek, M[iroslav] (2017). Using of Waterjet Technology for Cutting Aluminum Alloy, Proceedings of the 28th DAAAM International Symposium, pp.0486-0492, B. Katalinic (Ed.), Published by DAAAM International, ISBN 978-3-902734-11-2, ISSN 1726-9679, Vienna, Austria DOI: 10.2507/28th.daaam.proceedings.068

[11] Sogorovic, D[anijel] \& Knezevic, A[nica] (2019). Testing of the Surface Roughness Parameters of AluminiumLithium Parts Machined by Milling, Proceedings of the 30th DAAAM International Symposium, pp.0148-0154, B. Katalinic (Ed.), Published by DAAAM International, ISBN 978-3-902734-22-8, ISSN 1726-9679, Vienna, Austria DOI: 10.2507/30th.daaam.proceedings.019 